\title{
Persistence of mucosal T-cell responses to herpes simplex virus type 2 in the female genital tract
}

\author{
CM Posavad ${ }^{1,2}$, L Zhao ${ }^{1,2}$, DE Mueller $^{1}$, CE Stevens ${ }^{3}$, ML Huang $^{2}$, A Wald ${ }^{1,2,3,4}$ and L Corey ${ }^{1,2,3}$
}

Relatively little is known about the human T-cell response to herpes simplex virus type 2 (HSV-2) in the female genital tract, a major site of heterosexual HSV-2 acquisition, transmission, and reactivation. In order to understand the role of local mucosal immunity in HSV-2 infection, T-cell lines were expanded from serial cervical cytobrush samples from 30 HSV-2-infected women and examined for reactivity to HSV-2. Approximately $3 \%$ of the CD3 + T cells isolated from the cervix were HSV-2 specific and of these, a median of $91.3 \%$ were CD 4 +, whereas a median of $3.9 \%$ were CD8 + . HSV-2specific CD4 + T cells expanded from the cervix were not only more frequent than CD8 + T cells but also exhibited greater breadth in terms of antigenic reactivity. T cells directed at the same HSV-2 protein were often detected in serial cervical cytobrush samples and in blood. Thus, broad and persistent mucosal T-cell responses to HSV-2 were detected in the female genital tract of HSV-2 + women suggesting that these cells are resident at the site of HSV-2 infection. Understanding the role of these T cells at this biologically relevant site will be central to the elucidation of adaptive immune mechanisms involved in controlling HSV-2 disease.

\section{INTRODUCTION}

Herpes simplex virus type 2 (HSV-2) is the major cause of genital herpes, one of the most common sexually transmitted infections worldwide and a significant risk factor of HIV acquisition. ${ }^{1}$ In the United States, $17 \%$ of people are seropositive for HSV-2 and 58\% are seropositive for HSV $-1{ }^{2}$ Elsewhere, the seroprevalence rate is much higher, reaching 95\% in some populations of HIV-infected persons and female sex workers (reviewed in Gupta et al. ${ }^{3}$ ). The lack of success of HSV-2 vaccines ${ }^{4-6}$ and the observation that HSV-2 reactivation can occur in persons taking standard or high doses of antiviral therapy $^{7}$ underscore the urgency of defining mechanisms of resistance in order to design strategies to prevent primary HSV-2 infection and reduce or eliminate reactivation of latent HSV-2.

Clinical and experimental data indicate an important role of the adaptive immune response, especially $\mathrm{T}$-cell responses, in controlling genital herpes infections. Persons with defects in cellular immunity have more severe HSV-2 infections. ${ }^{8-10}$ The observations that HSV-2 clearance from genital herpes lesions correlates temporally with the infiltration of CD8 T cells, ${ }^{11}$ functional HSV-2-specific CD4 + and CD8 + T cells populate the site of HSV-2 reactivation, ${ }^{12-14}$ and that functional CD8 + $\mathrm{T}$ cells persist in genital skin contiguous to sensory neuronal nerve endings, ${ }^{15-17}$ suggest a role of the peripheral mucosaladaptive immune response in controlling HSV reactivation. Mathematical modeling predicts prolonged duration and increased severity of HSV-2-shedding episodes is strongly associated with a low density of CD8 $+\mathrm{T}$ cells within genital skin. ${ }^{18}$ That the virus has devised numerous strategies to evade host innate and adaptive mechanisms of resistance to primary and recurrent HSV infection further emphasizes the importance of host immune mechanisms.

Although numerous human studies characterize the T-cell response to HSV-2 in blood, skin, and eye (reviewed in Ouwendijk et al. ${ }^{19}$ ), few studies address the local mucosal cellular immune response directed at HSV-2 in the female genital tract. ${ }^{20}$ In order to more comprehensively analyze the cervical resident T-cell response to HSV-2, T cells isolated and expanded from serial cytobrush samples were obtained from 30 HSV-2 + women and analyzed with respect to phenotype, antigenic reactivity, and persistence. Cervical cytobrush

\footnotetext{
${ }^{1}$ Vaccine and Infectious Disease Division, Fred Hutchinson Cancer Research Center, Seattle, WA, USA. ${ }^{2}$ Department of Laboratory Medicine, University of Washington, Seattle, WA, USA. ${ }^{3}$ Department of Medicine, University of Washington, Seattle, WA, USA and ${ }^{4}$ Department of Epidemiology, University of Washington, Seattle, WA, USA. Correspondence: CM Posavad (posavad@uw.edu)

Received 23 January 2014; accepted 7 May 2014; published online 11 June 2014. doi:10.1038/mi.2014.47
} 
sampling is a relatively non-invasive procedure for obtaining mucosal $\mathrm{T}$ cells from the female genital tract and short-term polyclonal expansion of these cells allowed a more detailed characterization of cervically derived T cells to HSV-2.

\section{RESULTS}

\section{Clinical and demographic characteristics of study participants}

The study group consisted of 32 female participants in total including 2 who were seronegative to HSV-1 and HSV-2 (HSVneg) and 30 who were seropositive to HSV-2 (HSV-2 + ): of these $30 \mathrm{HSV}-2+$ participants, 9 were coinfected with HSV-1 and HSV-2 (HSV-1+/2+), whereas 21 were seropositive to HSV-2 only (HSV $-1-/ 2+$ ) (Table 1). The average age of HSV + participants was 35 years (range 19-73 years) and the HSVneg participants were 26 and 51 years old. Most HSV-2 + participants were white (84\%) and had been infected with HSV-2 a median of 8.3 years (range $0.2-37.9$ years) (Table 1).

Table 1 Demographic and clinical characteristics of study participants

\begin{tabular}{lcc}
\hline & HSV-2 + & HSVneg \\
\hline No. of participants & 30 & 2 \\
Median age: years (range) & $35(19-73)$ & $39(26,51)$ \\
& & \\
HSV serostatus: $n$ (\%) & $21(70 \%)$ & NA \\
HSV-1 - / + & $9(30 \%)$ & NA \\
HSV-1 + $/ 2+$ & $30(100 \%)$ & NA \\
Total HSV-2 + & 25 White, 5 Black & 2 White \\
Race & $8.3(0.2-37.9)$ & NA \\
Years infected with HSV-2: median (range)
\end{tabular}

Abbreviations: HSV-2, herpes simplex virus type 2; NA, not available.

\section{HSV-specific lymphoproliferative (LP) responses in cervical lymphocytes}

All study participants (2 HSVneg, $30 \mathrm{HSV}-2+$ ) provided two cervical cytobrush samples spaced approximately 1 month apart. A median of $0.2 \times 10^{6}$ mononuclear cells (range $0.08 \times 10^{6}-1.8 \times 10^{6}$ cells) per cytobrush were obtained ex vivo. Of the 64 cytobrush samples, 1 was discarded owing to red blood cell contamination and $\mathrm{T}$ cells could not be expanded from 13 of the samples; cells could not be expanded from either of the two cytobrushes from three HSV-2+ participants (participants 7, 16, and 30) (Figure 1). The remaining 51 cervical cytobrush samples (48 from HSV-2 + participants, 3 from HSVneg participants), where cell growth was evident after 18-24 days in culture, were tested for HSVspecific T-cell activity by LP assays. Of the 48 samples from the HSV-2 + participants, where cell growth was evident, 31 or $65 \%$ proliferated in response to HSV-2; 26 of these also proliferated in response to HSV-1 (Figure 1). Considering only those subjects with samples containing HSV-2-specific LP responses, of the subjects who were seropositive for HSV-1 and HSV-2 $(n=5), 1(20 \%)$ had no LP responses to HSV-1, whereas $4(80 \%)$ had LP responses to both HSV-1 and HSV-2. Similarly, of the subjects who were seropositive for HSV-2 only $(n=16), 4$ (25\%) had no LP response to HSV-1, whereas 12 (75\%) had LP responses to both HSV-1 and HSV-2; these results suggest that HSV serostatus did not influence the ability to detect HSV-1specific LP responses in the cervical T-cell lines. From 10 of the 30 HSV-2 + participants, cervical T-cell lines were positive for LP responses to HSV-2 from both cytobrush samples, whereas cervical T-cell lines from $17 \mathrm{HSV}-2+$ participants had positive LP responses in only 1 cytobrush sample (Figure 1). Although $\mathrm{T}$ cells expanded from 3 of the 4 cytobrush samples obtained from the 2 HSVneg participants, none were positive for LP responses to HSV-1 or HSV-2 (Figure 1), although LP responses to PHA were positive in the 3 samples (data not

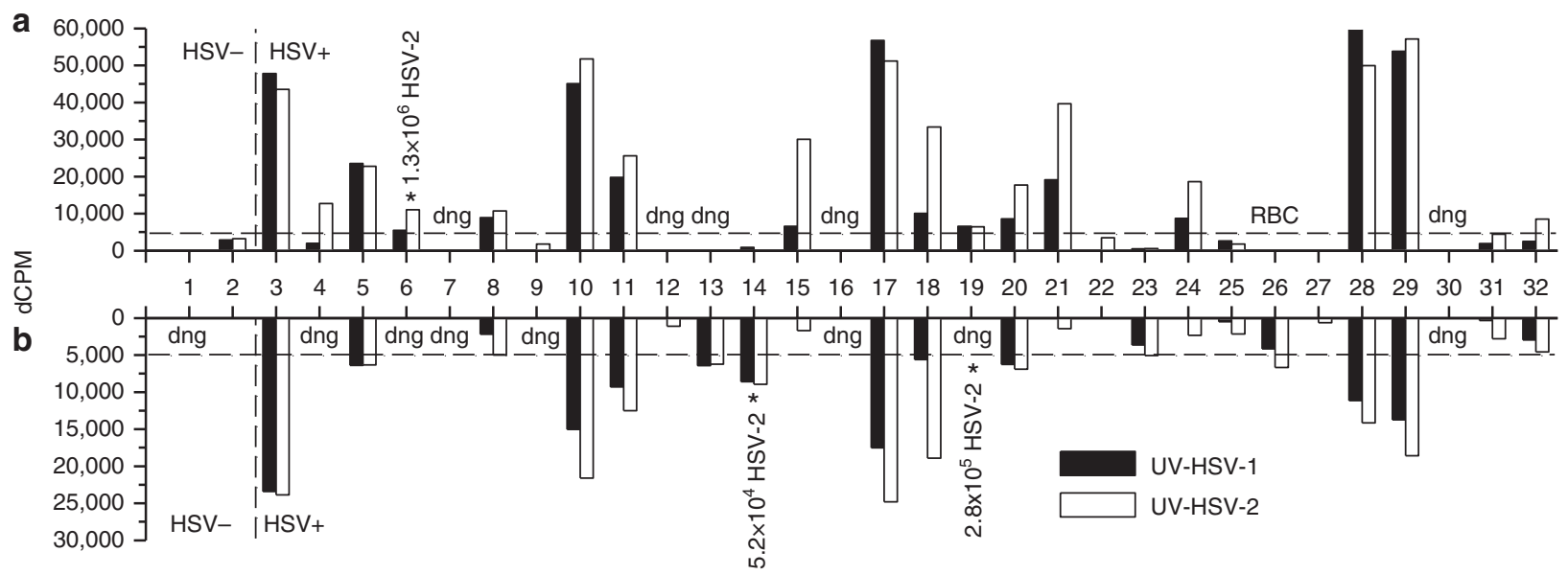

Figure 1 Herpes simplex virus (HSV)-specific LP responses in cervical cytobrush samples. Cervical cytobrush samples were obtained from 2 HSVneg (HSV - ) participants and 30 HSV-2 + participants at study entry (a) and at 1 month (b). Cervical T-cell lines expanded from these samples were tested for HSV-specific LP responses using UV-HSV-1 or UV-HSV-2 as the stimulatory antigen. Dashed line represents threshold for positivity ( $>5,000 \mathrm{dCPM}$ ). HSV-2 DNA was detected in three samples $\left({ }^{*}\right)$ and the total amount of virus detected in the sample is displayed. dng, did not grow; RBC, red blood cell contamination. 
shown). LP responses to HSV-1 ranged from 1- to 61,827 dCPM (median 5,491 dCPM), responses to HSV-2 ranged from 1 to $57,088 \mathrm{dCPM}$ (median 6,696 dCPM), and PHA responses ranged from 0 to 180,774 dCPM (median 28,890 dCPM): cells expanded from one sample (participant 15, second cytobrush sample) did not proliferate in response to PHA. An additional cytobrush sample was obtained from $5 \mathrm{HSV}-2+$ participants $\sim 6$ months after the first sample; $\mathrm{T}$ cells expanded in all five samples and all had positive LP responses to HSV-1, HSV-2, and PHA (data not shown).

\section{HSV-2 DNA in cervical samples}

Cervicovaginal lavage (CVL) fluid was collected from both clinic visits from each participant and tested for the presence of HSV-2 DNA by quantitative real-time PCR. Of the $60 \mathrm{CVL}$ collected from the $30 \mathrm{HSV}-2+$ participants, 3 samples (5\%) from 3 different participants tested positive for HSV-2 DNA (Figure 1). From the three visits where CVL were positive, low levels of HSV2 -specific LP were detected in the corresponding cytobrush samples from two of the participants (participant 6, visit 1; participant 14, visit 2), whereas $\mathrm{T}$ cells did not grow from the corresponding cytobrush sample from the third participant (participant 19, visit 2) (Figure 1). It was interesting to note that HSV-2 DNA was not detected in any CVL sample when a corresponding cytobrush sample possessed a high level of HSV-2specific LP. As expected, no HSV-2 DNA was detected from the four CVL collected from the HSVneg participants (Figure 1).

\section{HSV-2 proteins recognized by cervical T-cell lines}

Cervical T-cell lines that tested positive for HSV-specific LP responses were subsequently tested by interferon (IFN) $-\gamma$ enzyme-linked immunospot assay (ELISPOT) for reactivity to a panel of $34 \mathrm{HSV}$-peptide pools representing $16 \mathrm{HSV}-2$ proteins. Figure 2a displays two representative IFN- $\gamma$ ELISPOT assays from two cytobrush samples obtained 1 month apart from HSV-2 participant 17. Multiple HSV-2 peptide pools were recognized by the cervical $\mathrm{T}$-cell lines from each date (11 pools from 19 July 2010 and 12 pools from 20 August 2010) and multiple sub-pools from an individual HSV2 protein were also recognized (UL39, UL19, and UL46). In addition, IFN- $\gamma$ ELISPOT responses to eight of the HSV-2 peptide pools were detected in both cytobrush samples (Figure 2a). In total, 33 cytobrush samples from 19 HSV-2 participants were analyzed by IFN- $\gamma$ ELISPOT: 5 of these
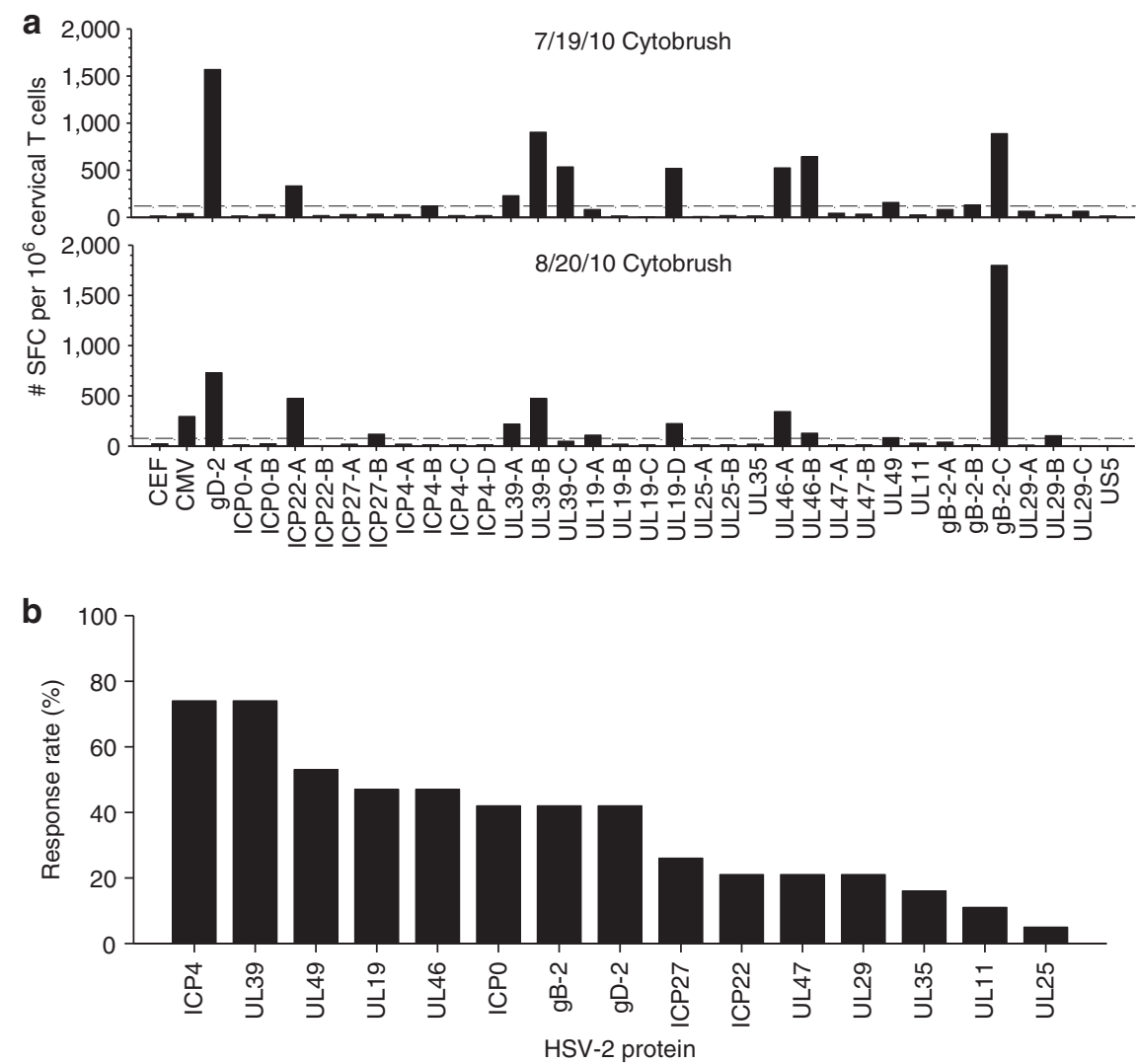

Figure 2 Antigenic diversity of herpes simplex virus type 2 (HSV-2)-specific T cells in cervical T-cell lines. (a) Cervical T-cell lines that were positive by HSV-LP from HSV-2 + Participant 17 obtained on 19 July 2010 (top) and 20 August 2010 (bottom) were stimulated with HSV-2, a peptide pool containing epitopes from cytomegalovirus, Epstein-Barr virus and influenza (CEF), or a cytomegalovirus pp65 peptide pool and tested for reactivity by interferon (IFN)- $\gamma$ enzyme-linked immunospot assay (ELISPOT); Y-axis is net spot-forming cells (SFC) per million cervical T cells (SFC in dimethyl sulfoxide (DMSO) control wells were subtracted). Dashed lines represent the threshold for positivity $(4 \times$ median of DMSO control wells and $\geq 55$ SFCs per million cervical T cells). (b) Cervical T-cell lines from HSV-2 + participants that were positive by HSV-LP were screened for reactivity using the 34 peptide pools representing $16 \mathrm{HSV}-2$ proteins by IFN- $\gamma$ ELISPOT. The frequency of detecting HSV-2 protein-specific T-cell responses in one or both cervical cytobrush samples from 19 HSV-2 + participants is displayed: HSV-2 proteins are stratified based on their hierarchy in \% response rate. 
ARTICLES

participants had 3 cytobrush samples screened, 4 of these participants had 2 cytobrush samples screened, whereas 10 had 1 cytobrush sample screened (Table 2). Positive IFN- $\gamma$ ELISPOT responses to $>1$ sub-pool of an individual HSV2 protein are grouped together. The median number of HSV-2 proteins recognized in individual cytobrush samples was 4 (range 1-11) (Table 2). The HSV-2 proteins most frequently recognized by cervical T-cell lines (positive in one, two, or three cytobrush samples) were ICP4 (74\%), UL39 (74\%), UL49 (53\%), UL46 (47\%) and UL19 (47\%), ICP0 (42\%), gD-2 (42\%), and gB-2 (42\%), (Table 2; Figure rb). This underestimates the total number of HSV-2 epitopes recognized because in many cases, $>1$ sub-pool from an individual HSV-2 protein was positive for a given cervical T-cell line: 11 cervical T-cell lines recognized $>1$ sub-pool of UL39 $(5$ recognized 2 sub-pools and 6 recognized 3 sub-pools), whereas 5 cervical T-cell lines recognized both sub-pools of UL46 (Figure aa and data not shown). Interestingly, T cells directed at the same HSV-2 protein were often detected in serial cytobrush samples: 8 of the 9 participants who had 2-3 cytobrush samples positive for HSV-LP responses had T-cell responses directed at the same HSV-2 protein in $>1$ cytobrush sample; $\sim 1 / 2$ of the IFN- $\gamma$

Table 2 Antigenic reactivity of cervical T-cell lines

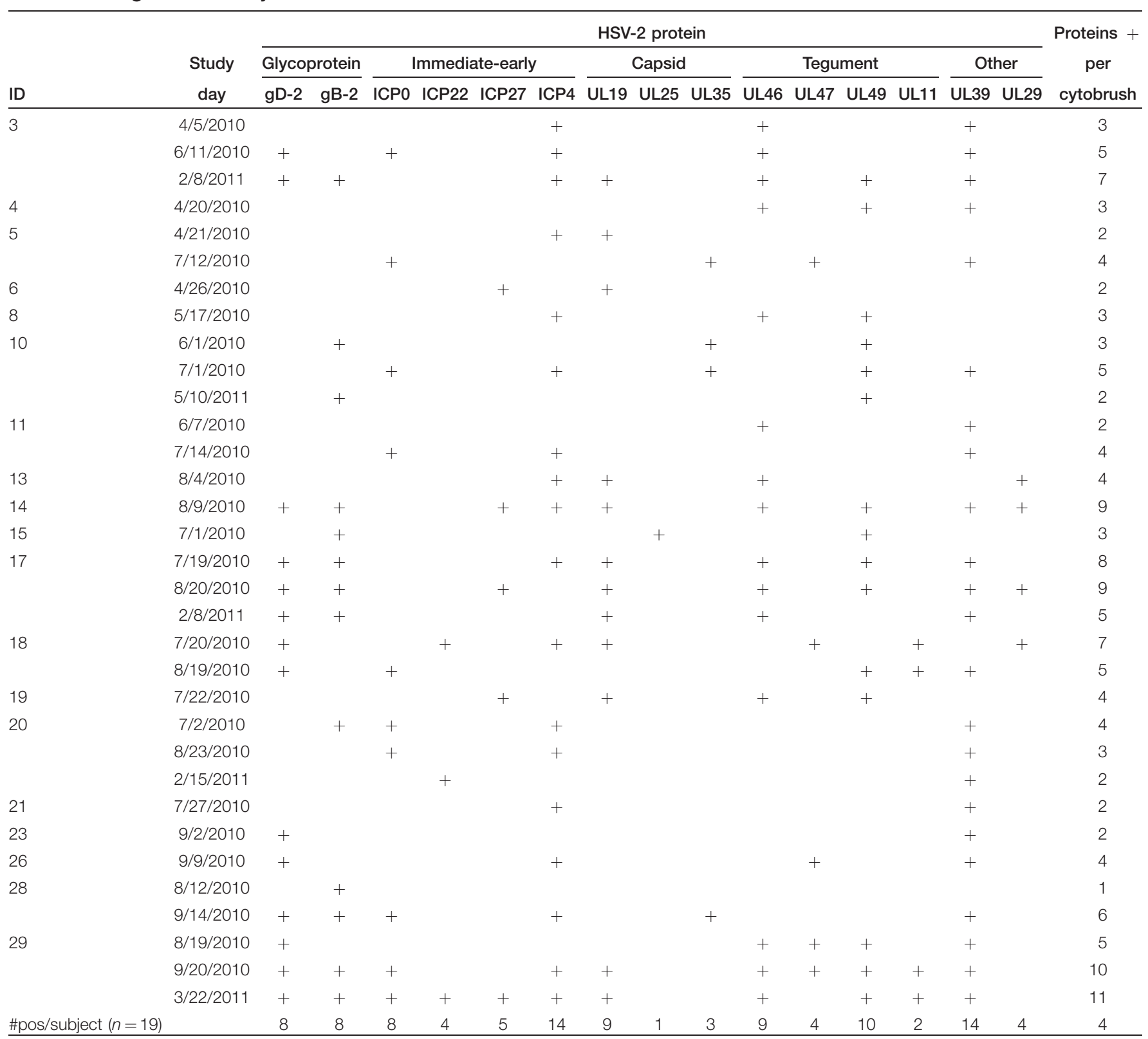

Abbreviations: HSV-2, herpes simplex virus type 2; IFN- $\gamma$ ELISPOT, interferon- $\gamma$ enzyme-linked immunospot assay.

Cervical T-cell lines from HSV-2 + participants with positive HSV-2-specific lymphoproliferative responses were screened by IFN- $\gamma$ ELISPOT using 34 pools of overlapping peptides representing $16 \mathrm{HSV}-2$ proteins that are classified as glycoproteins, immediate-early, capsid, tegument, or other proteins. Positive IFN- $\gamma$ ELISPOT responses to sub-pools are grouped together. +, positive IFN- $\gamma$ ELISPOT response; shaded cells, T cells directed at the same HSV-2 protein detected in $>1$ cytobrush sample from the same participant.

118

VOLUME 8 NUMBER 1 | JANUARY 2015 | www.nature.com/mi 
ELISPOT responses to a given HSV-2 protein were detected in $>1$ cytobrush sample from the same participant (Table 2; Figure 2a).

\section{HSV antigenic specificity of cervical T cells vs. blood- derived $\mathrm{T}$ cells}

To compare the breadth of the HSV-2-specific T-cell response between the cervix and blood, serial cytobrush samples and corresponding peripheral blood mononucleated cells (PBMC) were tested for reactivity to the HSV-2 peptide pools using IFN$\gamma$ ELISPOT. Figure 3 displays data from a representative HSV$2+$ participant: positive IFN- $\gamma$ ELISPOT responses were measured to multiple HSV-2 peptide pools and positive responses to the ICP4-D, UL39-B, and UL46-A sub-pools were present in all four samples (Figure 3). In addition, positive IFN- $\gamma$ ELISPOT responses to UL46-A were measured in both compartments on 5 April 2010 (Figure 3a,c), whereas positive IFN- $\gamma$ ELISPOT responses to gD-2 were detected in both compartments on 11 June 2010 (Figure 3b,d). Figure 4 displays the cumulative IFN- $\gamma$ ELISPOT response to HSV-2 in cervically derived (top) and blood-derived (bottom) $\mathrm{T}$ cells from nine HSV-2 + participants who had two cytobrush samples positive for HSV-specific T-cell activity; only those proteins with positive IFN- $\gamma$ ELISPOT responses are included and positive responses to sub-pools are grouped together. In general, cervically derived T-cell responses were broader in terms of antigenic reactivity compared with those measured in the corresponding PBMC samples. In all but three cases (5 April 2010 sample from participant 3, 12 August 2010 sample from participant 28, and 21 April 2010 sample from participant 5), cervically derived $\mathrm{T}$ cells were reactive to more HSV -2 proteins than the corresponding PBMC-derived T cells (Figure 4): a median of five HSV-2 proteins (range 1-10) were recognized by these cervically derived $\mathrm{T}$-cell lines compared with a median of three HSV-2 proteins (range 0-6) recognized by PBMC-derived T cells, although this was not statistically significant $(P>0.05)$. Similar antigenic reactivity patterns were observed between serial cytobrush samples from the same participant and often IFN- $\gamma$ ELISPOT responses were positive in both compartments. UL39 was the most commonly recognized HSV-2 protein: T cells directed at UL39 were detected in all cytobrush samples from these nine participants and in at least one PBMC sample from eight of the participants (Figure 4). The frequency of the cumulative $\mathrm{T}$-cell response was at least an order of magnitude greater in the cervix compared with the blood suggesting that $\mathrm{T}$ cells are enriched in this mucosal compartment.

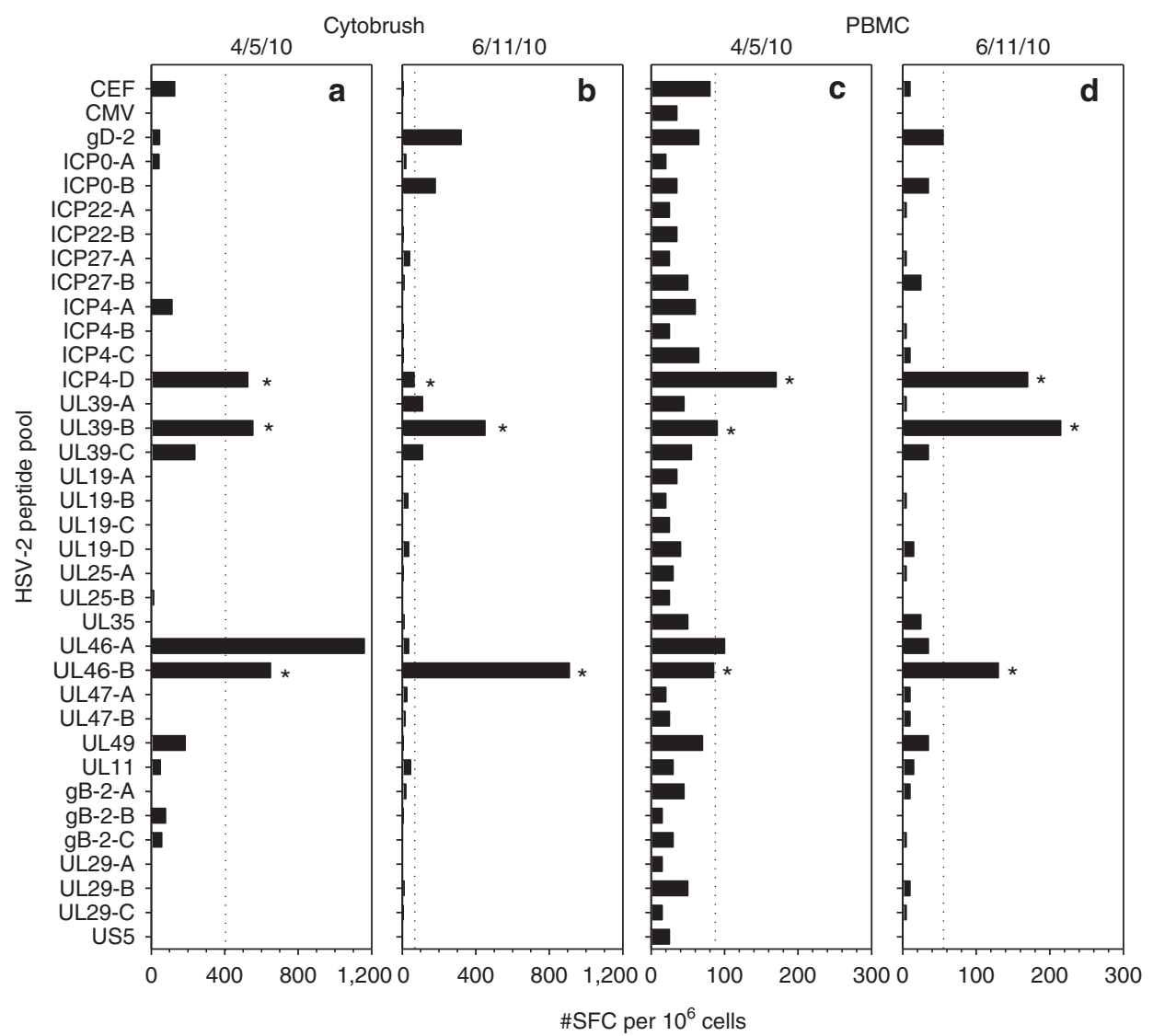

Figure 3 Interferon (IFN)- $\gamma$ T-cell response to herpes simplex virus type 2 (HSV-2) peptide pools in blood and genital tract of HSV-2 + women. Cervical T-cell lines (a and b) and PBMC (c and d) from HSV-2 + participant 3 obtained on 5 April 2010 (a and c) or 11 June 2010 (b and d) were screened by IFN- $\gamma$ enzyme-linked immunospot assay for reactivity to the HSV-2 peptide pools. X-axis is net spot-forming cells (SFC) per million cervical T cells (a and $\mathbf{b}$ ) or peripheral blood mononucleated cells (PBMC) (c and d) (SFC in dimethyl sulfoxide control wells were subtracted). Dashed lines represent the threshold for positivity as described in Figure 2a. *, individual HSV-2 peptide pool responses detected in all four samples from the two different compartments. $\mathrm{CEF}$, cytomegalovirus, Epstein-Barr virus and influenza. 


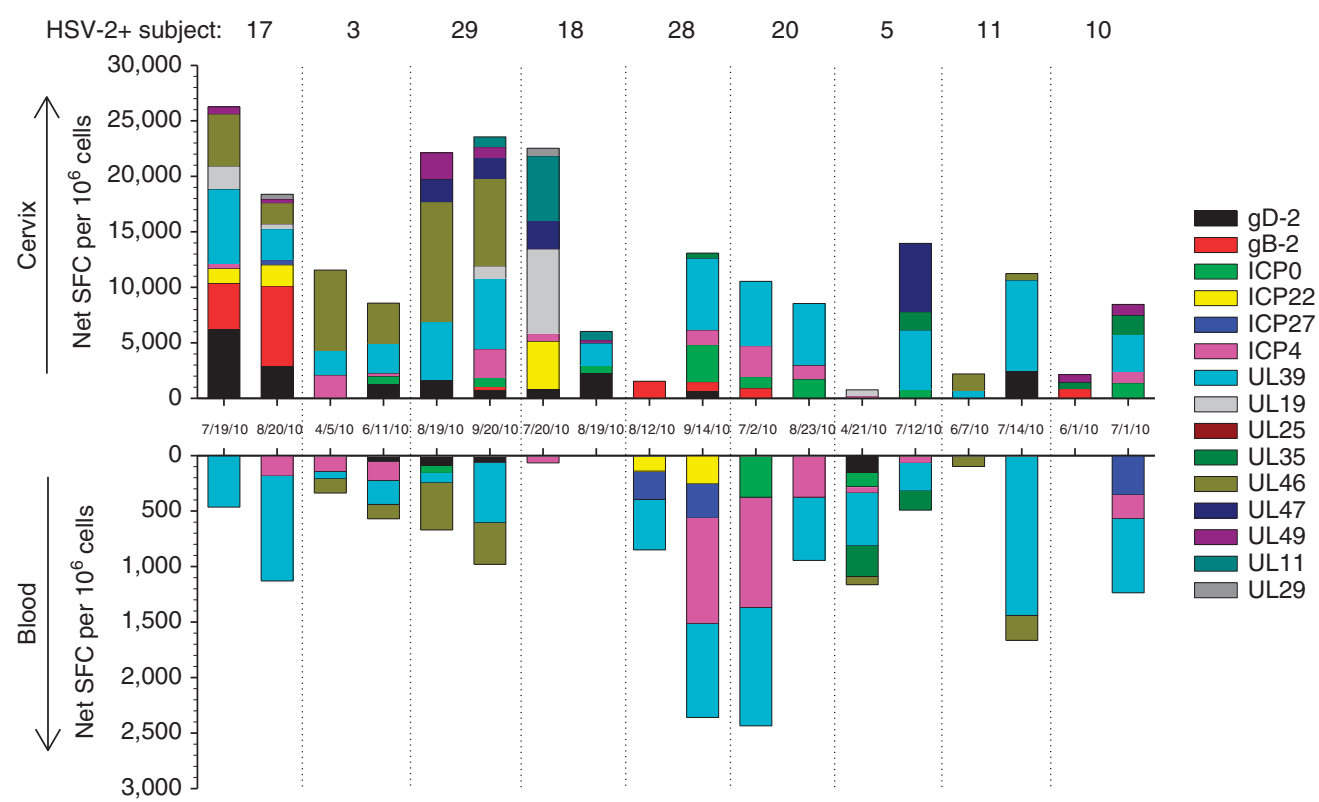

Figure 4 Cumulative interferon (IFN)- $\gamma$ T-cell response to herpes simplex virus type 2 (HSV-2) in blood and genital tract of HSV-2 + women. IFN- $\gamma$ enzyme-linked immunospot assay responses to HSV-2 peptide pools were measured in serial cervical T-cell lines and peripheral blood mononucleated cells from nine HSV-2 + women. Each bar represents an individual woman's response in the cervix or blood on the date displayed; the SFC from background wells (dimethyl sulfoxide) is subtracted from each HSV-2 peptide pool that is considered positive and only data from those pools that are positive are displayed.

Phenotype of HSV-2-specific T cells derived from the cervix Cervical T-cell lines that tested positive for HSV-2-specific LP responses were subsequently stimulated with autologous dendritic cells (DCs) that were mock infected or infected with HSV-2, and the expression of CD3, CD4, CD 8 , and IFN- $\gamma$ were measured by intracellular cytokine staining (ICS) and flow cytometry. Figure 5 displays data from two representative HSV $-2+$ participants, participants 5 and 19. Low background staining $(<0.10 \%)$ was observed to mock DC in both participants (left panels); in contrast, $4.47 \%$ of the CD3+ cells from participant 5 and $0.78 \%$ of $\mathrm{CD} 3+$ cells from participant 19 co-expressed IFN- $\gamma$ in response to exposure to HSV-2 (Figure 5, center panels). In participant 5, 37.5\% of the $\mathrm{CD} 3+/ \mathrm{IFN}-\gamma+$ cells were CD $4+$ and $58.9 \%$ were CD8 + ; in participant $19,86.5 \%$ of the CD3 $+/$ IFN $-\gamma+$ cells were CD $4+$ and $11.4 \%$ were CD $8+$ (Figure 5, right panels). In total, HSV2 -specific CD3 $+/$ IFN- $\gamma+$ cells were detectable in 25 of the cervical T-cell lines that possessed HSV-2-specific LP responses (Figure 6); the frequency of HSV-2-specific CD3 $+/ \mathrm{IFN}-\gamma+$ from 11 of the cervical T-cell lines that possessed HSV-2specific LP responses were below the level of detection in our ICS/flow cytometry assay and are not included in Figure 6. The median frequency of HSV-2-specific CD3 $+/$ IFN- $\gamma+$ T cells detected in the cervical $\mathrm{T}$-cell lines was $2.95 \%$ (range $0.45-$ 31.39\%; background subtracted) (Figure 6a). The HSV-2specific $\mathrm{CD} 3+/ \mathrm{IFN}-\gamma+$ population was predominantly comprised of CD $4+\mathrm{T}$ cells: a median of $91.30 \%$ (range $30-99.40 \%)$ of this population was CD4 + , whereas a median of $3.90 \%$ was $\mathrm{CD} 8+$ (range $0-67.70 \%) \quad(P=0.0012)$ (Figure 6b). Not only was the viral-specific CD3 + T-cell response comprised primarily of $\mathrm{CD} 4+\mathrm{T}$ cells, but the composition of the total T-cell population was also predominantly $\mathrm{CD} 4+$ : a median of $74.8 \%$ of the total $\mathrm{T}$ cells expanded from the cervical cytobrushes was CD4+ (range $42.7-98.6 \%$ ), whereas a median of $12.8 \%$ was CD8 + (range 1.2-52.6\%) $(P=0.00044)$ (Figure 6c). The proportion of total CD4 + T cells that were HSV-2 specific was $2.63 \%$ (median; range $0.24-30.14 \%$ ), whereas the proportion of total $\mathrm{CD} 8+\mathrm{T}$ cells that were HSV-2 specific was $0.79 \%$ (median; range $0-8.79 \%$ ) (data not shown).

\section{Phenotype of cervical T cells reactive to HSV-2 peptide pools}

To determine whether cervical T cells responding to the HSV-2 peptide pools were CD $4+$ or $\mathrm{CD} 8+$, cervical T-cell lines were incubated with the HSV-2 peptide pools that tested positive by IFN- $\gamma$ ELISPOT, and phenotypes of the responding cells were measured by ICS and flow cytometry. As displayed in representative histograms in Figure 7a, seven of the HSV-2 peptide pools that were positive in the 19 July 2010 cytobrush from HSV-2 participant 17 were recognized by CD $4+\mathrm{T}$ cells (gD-2, UL39-B, UL39-C, UL19-D, UL46-A, UL46-B, and gB-2$\mathrm{C})$, whereas two pools were recognized by $\mathrm{CD} 8+\mathrm{T}$ cells (ICP22-A and gB-2-C). In total, 28 cervical T-cell lines from 17 participants were analyzed for the phenotype of the responding T cells: 4 participants had 3 cervical T-cell lines, 3 participants had 2 cervical T-cell lines, and 10 participants had 1 cervical $\mathrm{T}$ cell analyzed. There were a total of 133 positive responses to individual HSV -2 peptide pools that could be measured by ICS and flow cytometry from all 28 cervical T-cell lines; 105 of these 

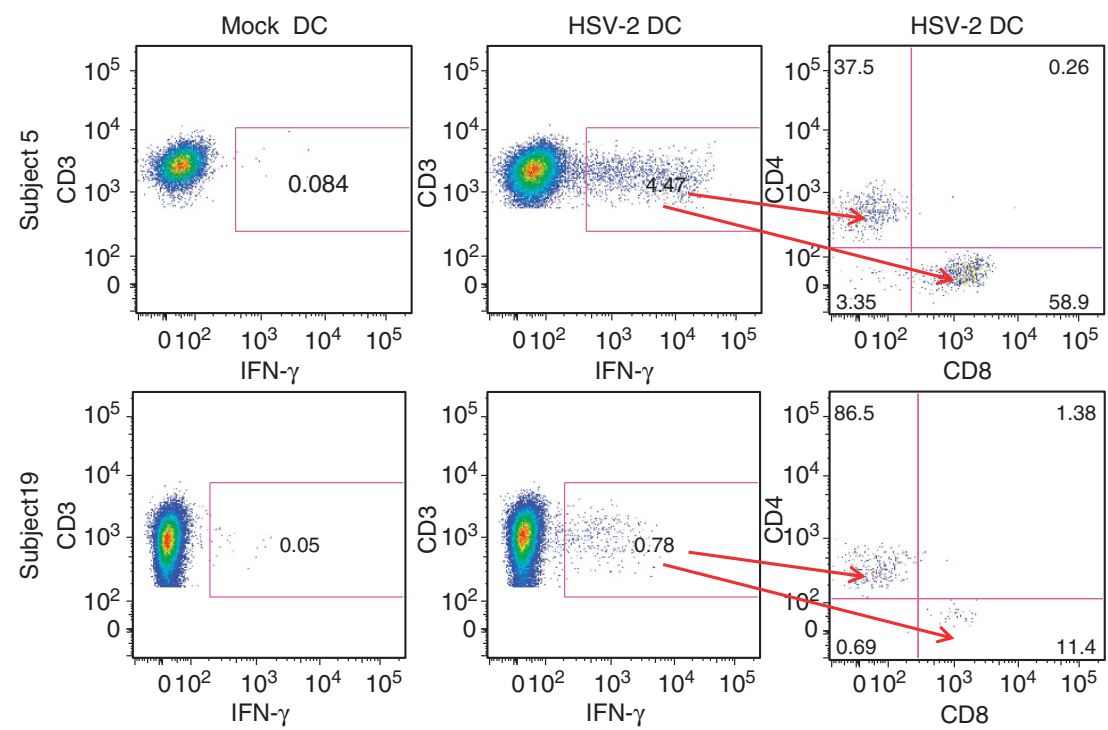

Figure 5 Phenotype of cervically derived T cells reactive to herpes simplex virus type 2 (HSV-2). Cervical T-cell lines expanded from two HSV-2 + participants (participant 5 and participant 19) were stimulated with a mock dendritic cell (DC) or HSV-2 DC and the production of interferon (IFN)- $\gamma$ from CD3 + cells was determined. Far right graphs display the percentages of CD4 + and CD8 + T cells within the HSV-2-reactive CD3 $+/$ IFN- $\gamma+$ population.
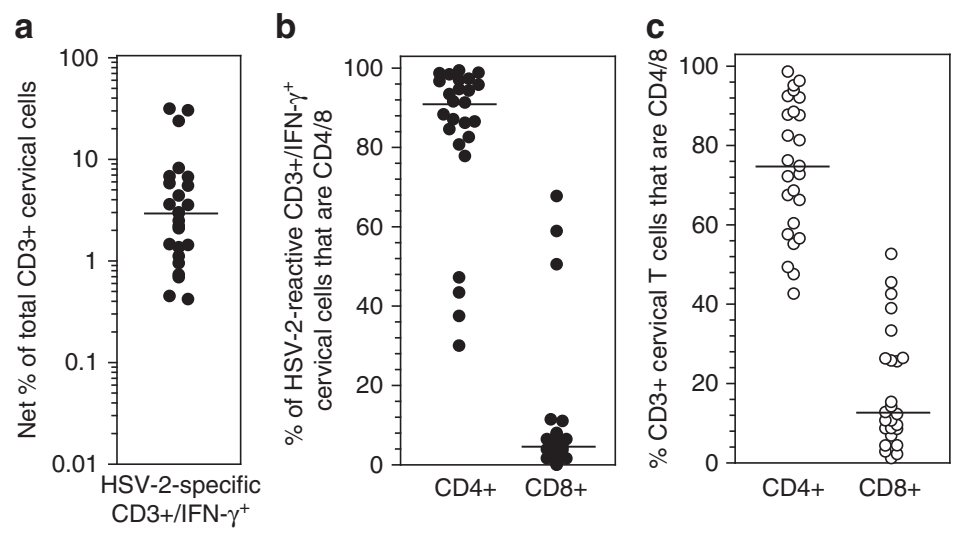

Figure 6 Frequency of CD3, CD4, and CD8 T-cell responses to herpes simplex virus type 2 (HSV-2) in T cells derived from the cervix. Cervical T-cell lines were incubated with a mock dendritic cell (DC) or HSV-2 DC and the expression of CD3, CD4, CD8, and interferon (IFN)- $\gamma$ was determined by intracellular cytokine staining and flow cytometry. (a) The proportion of cervically derived CD3 + T cells that were HSV-2 specific was calculated by subtracting $\% \mathrm{CD} 3+\mathrm{IFN}-\gamma+$ cells with mock DC from $\% \mathrm{CD} 3+/ \mathrm{IFN}-\gamma+$ cells with HSV-2 DC. (b) The percentages of CD $4+$ and CD8 + T cells within the HSV-2-reactive CD3 +/IFN- $\gamma+$ fraction from (a) is displayed. (c) The proportion of total cervically derived CD3 + T cells that were CD4 + or CD8 + is displayed. In each graph, median frequencies are displayed by the dashed line.

were $\mathrm{CD} 4+$ and 28 were CD8 + . On an individual basis, CD4 $\mathrm{T}$ cells derived from a cervical $\mathrm{T}$-cell line were reactive to an average of three different HSV-2 peptide pools (range 0-13) compared with $\mathrm{CD} 8 \mathrm{~T}$ cells that were reactive to an average of one HSV-2 peptide pool (range $0-4) \quad(P=0.00044)$. In Figure $7 \mathbf{b}$, all CD4 and CD8 responses to individual HSV2 proteins from all 17 participants were grouped together to assess the $\mathrm{CD} 4 / \mathrm{CD} 8$ phenotype of $\mathrm{T}$ cells responding to the HSV-2 proteins; when a CD4 or CD8 response to an individual HSV- 2 protein was detected in $>1$ cytobrush sample from the same individual, we only included this response once. On a population level, CD4 responses were directed at a broader range of HSV-2 proteins compared with CD8 responses (Figure $7 \mathbf{b}$ ). Figure $7 \mathrm{c}$ displays pie graphs depicting the percentage of the total number of CD4 (top) or CD8 (bottom) responses directed at individual HSV-2 proteins. UL39 was the most common HSV-2 protein recognized by both CD4 and CD8 $\mathrm{T}$ cells derived from the cervix (Figure $7 \mathbf{b}, \mathbf{c}$ ). CD8 responses were also commonly directed at ICP0, ICP4, UL46, and UL49 (Figure $7 \mathbf{b}, \mathbf{c}$ ), whereas CD4 responses were commonly directed at gB-2, gD-2, UL19, UL46, and ICP4 (Figure $7 \mathbf{b}, \mathbf{c})$. Taken together, these data suggest a greater antigenic diversity in the cervically derived CD4 T-cell response compared with the cervically derived CD8 T-cell response to 

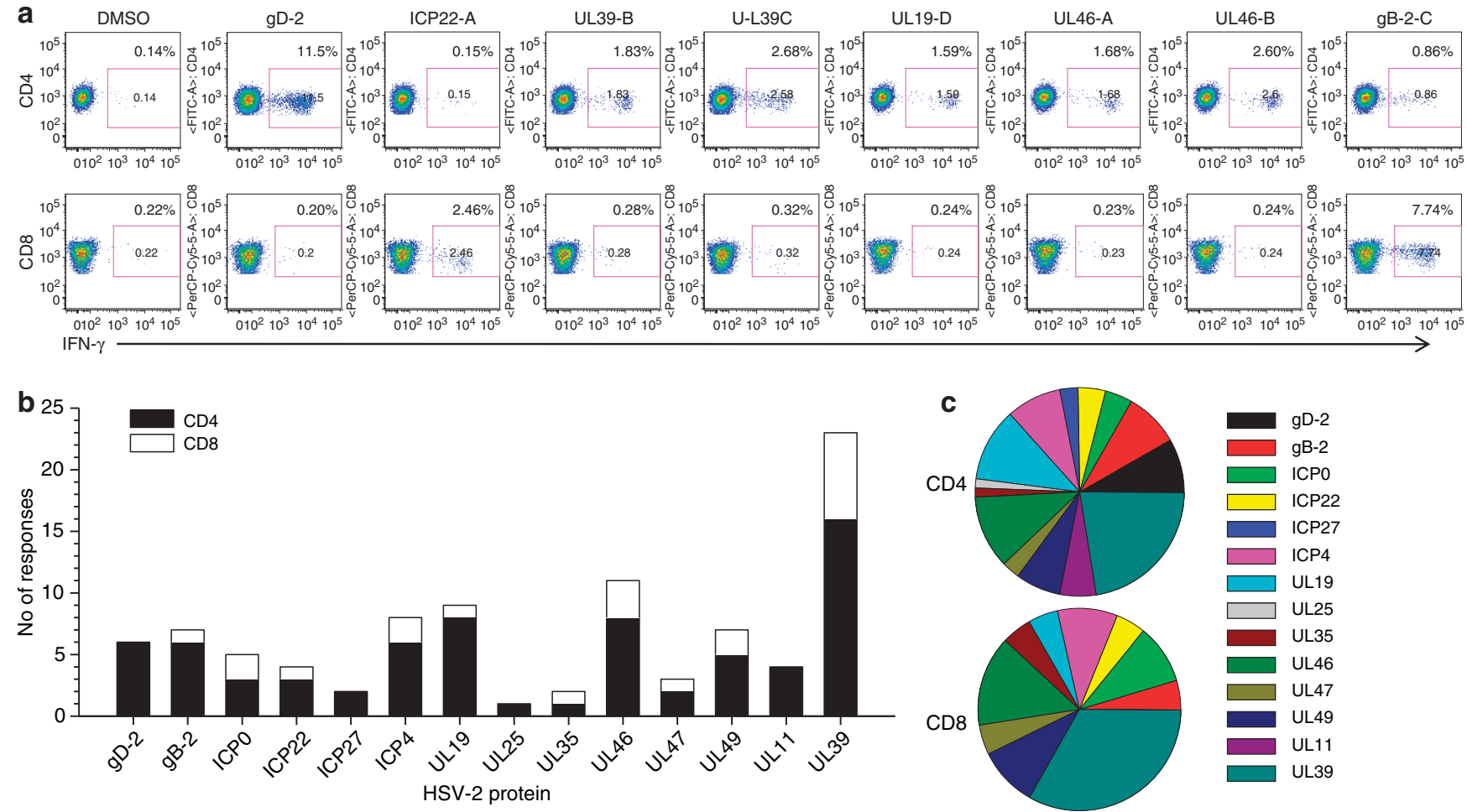

Figure 7 Antigenic diversity of herpes simplex virus type 2 (HSV-2)-specific CD4 and CD8 T-cell responses in cervical T-cell lines. (a) The expanded cervical T-cell line from HSV-2 + participant 17 from the cytobrush sample obtained on 19 July 2010 (Figure 3a, top graph) was stimulated with dimethyl sulfoxide (DMSO) only (negative control) or one of the HSV-2 peptide pools that were positive in interferon (IFN)- $\gamma$ enzyme-linked immunospot assays and the phenotype of reactive cells was determined using intracellular cytokine staining (ICS)/flow cytometry. Top row of the graphs are CD4 vs. IFN- $\gamma$ and the bottom row of graphs are CD8 vs. IFN- $\gamma$; the percentage of CD4 +/IFN- $\gamma+$ or CD8 $+/$ IFN- $\gamma+$ cells is displayed. (b) Positive CD4 and CD8 responses to individual HSV-2 proteins measured in cervical T-cell lines from all HSV-2 + participants determined by ICS/flow cytometry were collated. Black bars, $\mathrm{CD} 4+/ \mathrm{IFN}-\gamma+$ responses, open bar, CD8 $+/ \mathrm{IFN}-\gamma+$ responses. (c) The percentage of CD $4+/ \mathrm{IFN}-\gamma+$ responses (top pie graph) and CD8 $+/ \mathrm{IFN}-\gamma+$ responses (bottom pie graph) directed at individual HSV-2 proteins present in cervical T-cell lines from HSV-2 + participants is displayed.

HSV-2 on both an individual and population basis. Thus, not only do $\mathrm{CD} 4+\mathrm{T}$ cells comprise a greater percentage of the HSV-2-specific $\mathrm{CD} 3+/ \mathrm{IFN}-\gamma+$ population within the cervical T-cell lines (Figure $6 \mathbf{b}$ ), but they are also directed at a broader range of HSV-2 proteins as compared with the $\mathrm{CD} 8+\mathrm{T}$ cells derived from the cervix (Figure $\mathbf{7 b}, \mathbf{c}$ ).

\section{DISCUSSION}

This study markedly extends the knowledge of HSV-2-specific $\mathrm{T}$ cells populating the human female genital tract. HSV-specific $\mathrm{T}$ cells were frequently detected in the cervix and $\sim 3 \%$ of all $\mathrm{T}$ cells expanded from the cervical cytobrush samples were directed at HSV-2. The HSV-2-specific T-cell response was predominantly comprised of $\mathrm{CD} 4 \mathrm{~T}$ cells, which were directed at a broader range of HSV-2 proteins compared with CD8 T cells. HSV-2-specific T cells appeared to be enriched in the cervix compared with the blood compartment, and T-cell responses directed at the same HSV-2 protein and peptide pool were often detected in serial cytobrush samples as well as in PBMC.

Total CD $4+\mathrm{T}$ cells and HSV-2-specific CD $4+\mathrm{T}$ cells were consistently detected in the cervical T-cell lines and at high frequencies compared with CD8 $+\mathrm{T}$ cells, which were present at significantly lower frequencies and sometimes undetectable. This observation is consistent with a comprehensive analysis of memory T-cell subsets within various peripheral tissues, which demonstrated that memory $\mathrm{CD} 4+\mathrm{T}$ cells represent the majority subset in mucosal tissue including the lung and intestinal tract, although the female genital tract was not analyzed. ${ }^{21} \mathrm{CD} 4+\mathrm{T}$ cells were shown to be present in high numbers in the endocervix in a distinct band underneath the epithelium $^{22}$ and a study of 30 healthy Caucasian women showed that $\mathrm{CD} 3+\mathrm{T}$ cells made up $\sim 1 \%$ of the total cells isolated from the endocervix and of those, $61 \%$ were $\mathrm{CD} 4+{ }^{23}$ A recent study by McKinnon et al. ${ }^{24}$ showed a 2:1 CD4:CD8 ratio in T cells isolated from healthy women in Seattle, Chicago, and Nairobi. Our study demonstrates that $\sim 75 \%$ of the total $\mathrm{CD} 3+$ population within the cervical T-cell lines were CD4+ (Figure 6c). These data suggest that the total T-cell population obtained upon cytobrushing is skewed toward CD4 $+\mathrm{T}$ cells. This dominance in CD4 $+\mathrm{T}$ cells is more pronounced in the HSV-2-specific CD3 + population, where a median of $91 \%$ of HSV-2-specific CD3 + T cells were CD4 + (Figure 6b). The presence of sexually transmitted infections has been shown to influence the T-cell composition in the cervix: higher numbers of $\mathrm{CD} 4+\mathrm{T}$ cells were measured in the endocervix in subjects 
with non-ulcerative sexually transmitted infections including chlamydia, gonorrhea, and trichomoniasis. ${ }^{25}$ However, because the non-specific stimulation of $\mathrm{T}$ cells isolated from the cervix may preferentially expand $\mathrm{T}$ cells with higher proliferative capacity, the most accurate assessment of the T-cell composition of both total T cells and HSV-2-specific T cells would be performed ex vivo. It is likely that a significant fraction of $\mathrm{CD} 8+\mathrm{T}$ cells are resident memory $\mathrm{T}$ cells that have limited proliferative capacity and thus unlikely to expand in our protocol requiring cells to undergo multiple rounds of cell division. The impact of expansion methods on the maturational state of cervical $\mathrm{T}$ cells in HIV + women suggested that expansion using anti-CD3, similar to the current study, led to the accumulation of effector memory $\mathrm{T}$ cells $(\mathrm{CD} 45 \mathrm{R} 0+$ CCR7 - CD27 - ) after 7 days ${ }^{26}$ however, these studies did not measure virus-specific responses but instead total CD4 and CD8 T cells. Our limited data analyzing cytobrush-derived T cells ex vivo for HSV-2-specific CD4 + and CD8 + T cells suggest that $\mathrm{CD} 8+\mathrm{T}$ cells were at lower frequencies than $\mathrm{CD} 4+\mathrm{T}$ cells or undetectable, similar to the phenotype of cervical $\mathrm{T}$-cell lines generated upon in vitro expansion (unpublished data). Interestingly, higher numbers of CD8 $+\mathrm{T}$ cells were present in ectocervical biopsy specimens compared with endocervical cytobrush specimens obtained from healthy women, ${ }^{24}$ suggesting that $\mathrm{CD} 8+\mathrm{T}$ cells may reside at tissue locations not sampled during cytobrushing and perhaps providing another possibility as to why low frequencies of HSV-2-specific CD8 + T cells were measured. In any event, although the presence of high frequencies of HSV-2-specific $\mathrm{CD} 4+\mathrm{T}$ cells in the cervix may suggest an important role in the local control of genital HSV-2 infection, it may also have significant implications for HIV acquisition as HSV-2 increases the risk of HIV acquisition, possibly owing in part to increased $\mathrm{CD} 4+\mathrm{T}$-cell activation in the cervix and an increased expression of HIV susceptibility markers, CCR5 and $\alpha 4 \beta 7^{27-29}$

HSV-2 disease is characterized by frequent clinical and subclinical shedding. The frequent detection and high frequency of HSV-specific T cells in the cervix suggests the ongoing exposure to an antigen, although cervical shedding of HSV-2 tends to occur at lower rates than from other areas of the lower genital tract. ${ }^{30}$ The current study detected HSV-2 DNA in only three of the cytobrush samples (5\% of samples); this is similar to what was observed in a cross-sectional study of 509 HSV-2 seropositive women where 7\% of all CVL samples were positive for HSV-2 DNA. ${ }^{31}$ The antimicrobial activity of CVL, which increases at the time of clinical HSV-2 outbreaks, has been proposed as a mechanism to prevent the spread of HSV-2 from external genital sites to the upper genital tract. ${ }^{32}$ The high frequency of HSV-2-specific cervical T cells detailed in the current study may contribute to the control of HSV-2 spread in the female genital tract; anecdotally, HSV-2 DNA was not detected in any CVL with a correspondingly high level of HSV-2-specific LP responses in the cytobrush samples. A more intense study of mucosal sampling, including multiple external and internal genital sites, and local $\mathrm{T}$ cells is warranted to assess the relationship between local mucosal HSV-specific
T-cell immunity and viral shedding in order to determine the mechanism of viral control at the site of infection and reactivation.

Short-term polyclonal expansion of the $\mathrm{T}$ cells obtained from cytobrushing provided sufficient cells to analyze the antigenic repertoire of cervical T-cell lines. In general, T-cell recovery was too low to perform ex vivo functional and other phenotypic T-cell studies. We have recently obtained cervical biopsies that may provide a larger source of cells that can be tested ex vivo to determine the memory/effector phenotype, cytokine profile, and lytic function of the cervical resident T cells; such studies are best done ex vivo to prevent changes in biologically relevant mechanisms that may be altered upon short-term and longterm cell culture. ${ }^{26,33}$ These ex vivo studies will aid in the determination of the mechanisms utilized by local $\mathrm{T}$ cells to limit or prevent HSV reactivation and spread in HSV-2infected participants or protection from infection in HSVresistant populations. Recently, our group demonstrated that $\mathrm{CD} 8 \alpha \alpha+\mathrm{T}$ cells are the dominant resident population of dermal-epidermal junction $\mathrm{CD} 8+\mathrm{T}$ cells that persist at the site of previous reactivation in skin near the genital region. ${ }^{17}$ Importantly, these cells (1) lacked the expression of CCR7 and S1PR1, suggesting that they may be tissue-resident $\mathrm{T}$ cells, and (2) possessed gene signatures of T-cell activation and antiviral activity suggesting a role in immune surveillance and in the containment of HSV-2 reactivation in human peripheral tissue. ${ }^{17}$ It will be important to determine whether these $\mathrm{CD} 8 \alpha \alpha+$ cells also persist in the human female genital tract as a means to control local HSV-2 reactivation; presumably, these cells lack significant proliferative potential and may not be expanded using the techniques employed in this study but instead may only be detected if assessed in situ or ex vivo.

UL39 and ICP4 were the most common HSV-2 proteins recognized by cervical T-cell lines, including both $\mathrm{CD} 4+$ and CD8 + T cells, from HSV $-2+$ participants. This is similar to what we have previously reported in blood-derived HSV-2specific CD8 + T cells from HSV-2 + participants $^{34,35}$ and immune seronegative participants. ${ }^{36}$ Studying the antigenic repertoire of local T-cell responses will be important for the rational design of prophylactic and therapeutic vaccines against HSV-2. Induction of local T-cell immunity will be an essential feature of any HSV-2 vaccine; frequent cervical cytobrushing was well tolerated by our study participants and may represent a viable strategy for assessing whether candidate HSV-2 vaccines elicit local adaptive immune responses. Although the design of therapeutic vaccines may be informed by the study of HSVinfected participants with the lowest rates of mucosal HSV reactivation ("virus controllers"), strategies for the prevention of HSV infection require the elucidation of protective mechanisms employed by participants who resist infection, especially those who remain seronegative even after frequent exposure to HSV from infected sexual partners. ${ }^{36,37}$ We are currently exploring whether local T-cell responses are present in these HSVneg participants in order to assess whether these responses may be linked to protection from HSV infection at the genital mucosa. 
The current study has utilized HSV-2 peptide pools representing 16 HSV-2 proteins commonly recognized by systemic and skin-derived T cells from HSV-2 + participants. HSV-2 encodes 80 open-reading frames (ORFs) and thus, the current study screens T cells directed at only $20 \%$ of the HSV-2 proteome. Dr David Koelle has developed an elegant method to efficiently generate a genome-wide map of the responsiveness to HSV-1-specific T cells ${ }^{38}$ and more recently, to HSV-2-specific T cells (unpublished data). This technology will provide a global analysis of both the CD4 and CD8 T-cell response to HSV-2. It is likely to reveal novel $\mathrm{T}$-cell epitopes recognized by cervically derived $\mathrm{T}$ cells and allow a precise comparison of the antigenic reactivity between $\mathrm{T}$ cells derived from the mucosa and blood.

In summary, this study assessed the frequency and antigenic profile of mucosal T-cell responses to HSV-2 in the human female genital tract using non-specific in vitro polyclonally expanded cervical cytobrush-derived $\mathrm{T}$ cells from HSV-2infected women. Local immunity at sites of HSV-2 exposure is likely to have an important role in preventing or controlling HSV reactivation or HSV infection and may inform the design of future HSV-2 vaccine strategies. Efficacious HSV-2 vaccines will require the elicitation of local T-cell immunity, and sampling the cervix for the detection of vaccine-induced T cells would be a feasible strategy and one of high priority to employ in future vaccine trials. Although the study of polyclonally expanded $\mathrm{T}$ cells has provided valuable insight into the phenotype and antigenic profile of local T-cell immunity to HSV-2, the study of local T cells ex vivo should provide mechanistic data that may lead to correlations of immune protection and novel strategies to suppress HSV-2 reactivation or prevent HSV-2 infection.

\section{METHODS}

Study population. Healthy HSV-1 and HSV-2 seronegative (HSVneg), HSV-1-seronegative/HSV-2 seropositive (HSV-1 - /2+), and HSV-1-seropositive/HSV-2-seropositive (HSV-1+/2+) female participants were enrolled into Institutional Review Board-approved protocols at the University of Washington Virology Research Clinic, Seattle, WA. All participants provided written informed consent. HSV western blot to detect antibodies to HSV-1 and HSV-2 was performed as previously described. ${ }^{39,40}$

PBMC, DC, lymphoblastoid cell lines and viruses. Peripheral blood mononuclear cells (PBMC) were isolated by Ficoll-Hypaque and cryopreserved within $8 \mathrm{~h}$ of venipuncture as previously described. ${ }^{41}$ DCs were generated from PBMC using granulocyte-macrophage colony-stimulating factor and interleukin- 4 as previously described. ${ }^{34}$ Lymphoblastoid cell lines were generated as previously described. ${ }^{42}$ HSV-1 strain E115 and HSV-2 strain 333 were used at a multiplicity of infection of 10 or were ultraviolet (UV)-inactivated to use as viral antigen where indicated.

Cervical mucosal sample collection, processing, and T-cell expansion. Cervical cells were collected during speculum examination using a Cytobrush Plus Cell Collector (Medscand, Malmo, Sweden) inserted into the cervical os, rotated through $360^{\circ}$ once, and immediately placed in $5 \mathrm{ml}$ of cold transport medium RPMI-CVX (RPMI 1640 medium supplemented with $5 \mathrm{~mm}$ l-glutamine, $50 \mathrm{U} \mathrm{ml}^{-1}$ penicillin, $50 \mu \mathrm{g} \mathrm{ml}^{-1}$ streptomycin, and $10 \%$ human serum, $10 \mu \mathrm{ml}^{-1}$ amphotericin $\mathrm{B}$, and $0.5 \mu \mathrm{lml} \mathrm{ml}^{-1}$ ciprofloxacin). Each participant provided two cervical cytobrush samples spaced $\sim 1$ month apart; five
HSV-2 + participants provided an additional cytobrush sample approximately 6-10 months post study entry. Cervical samples with visible red blood cell contamination were discarded. Under sterile conditions, cervical cells were isolated within $2 \mathrm{~h}$ of collection by gently vortexing the tube containing the cytobrush followed by rotating the cytobrush against the sides of the tube to dislodge cells. The transport medium was flushed through the cytobrush bristles and the cell suspension was passed through a $40-\mu \mathrm{M}$ filter into a clean $50-\mathrm{ml}$ centrifuge tube. Cells were pelleted at $250 \times g$ for $10 \mathrm{~min}$, resuspended in RPMI-CVX, and counted. Cervical cells were cultured in 24-well plates (up to $2 \times 10^{6}$ per well) along with $5 \times 10^{6}$ autologous irradiated PBMC, OKT3 ( $1 \mu \mathrm{lin} 25 \mathrm{ml}$ ) and CD28 $\left(0.5 \mu \mathrm{l} \mathrm{ml}^{-1}\right.$ ) (BD Biosciences, San Jose, $\mathrm{CA})$ in a final volume of $2 \mathrm{ml}$ per well. Interleukin-2 $\left(50 \mathrm{U} \mathrm{ml}^{-1}\right)$ was added every 2-3 days in fresh RPMI-CVX.

CVL fluid was obtained from each participant in order to measure HSV DNA by washing the cervical os and posterior vaginal wall with $10 \mathrm{ml}$ of phosphate-buffered saline (pH 7.0) as previously described. ${ }^{43}$ Samples were transported on ice and centrifuged at $1000 \times g$ for $20 \mathrm{~min}$ at $4{ }^{\circ} \mathrm{C}$, aliquoted, and stored at $-80^{\circ} \mathrm{C}$.

HSV-specific LP responses. Cervical T-cell lines were washed twice and $1 \times 10^{5}$ cells were incubated in triplicate with $1 \times 10^{5}$ irradiated autologous PBMC as antigen-presenting cells in 96-well round-bottomed plates. Cervical T-cell lines were stimulated with 1:500 dilution of UV-inactivated (UV) HSV-1, UV-HSV-2, mock antigen (Ag), or purified PHA $\left(0.4 \mu \mathrm{g} \mathrm{ml}^{-1}\right)$ (Murex, distributed by Remel, Lenexa, KS) as previously described. ${ }^{9}$ After 3 days, $1 \mu \mathrm{Ci}\left[{ }^{3} \mathrm{H}\right]$ thymidine (New England Nuclear, Boston, MA) was added to each well for $18 \mathrm{~h}$ and its incorporation into DNA was measured. $\Delta \mathrm{cpm}$ were calculated by subtracting cpm from mock Ag wells from cpm from UV-HSV wells. An LP response was considered positive if the $\Delta \mathrm{cpm}$ were $>5,000 \mathrm{cpm}$.

Synthetic peptides and peptide pools. We selected 16 HSV-2 ORFs for peptide synthesis as previously described. ${ }^{36}$ ORFs were mostly virion proteins (capsid, tegument, and glycoprotein) or immediateearly proteins. Amino-acid sequences were derived from the HSV-2 strain HG52 genome (GenBank accession no. NC-001798). Peptides were 15 amino acids long and overlapping by 11 amino acids and synthesized in crude form by either CBI/Mimotopes (San Diego, CA) (gD-2, ICP0, ICP4, ICP22, ICP27, and UL39) or New England Peptide LLC (Gardner, MA) (UL19, UL25, UL35, UL46, UL47, UL49, UL11, UL27, UL29, and US5) and lyophilized. Each peptide was dissolved in $10 \mathrm{mg} \mathrm{ml}^{-1}$ in sterile endotoxin-free dimethyl sulfoxide (Sigma, St Louis, MO) and stored at $4{ }^{\circ} \mathrm{C}$. The mass of each peptide was approximately 4-5 mg. Control peptide pools included a pool comprising immunodominant CD8 + T-cell epitopes within cytomegalovirus (CMV), Epstein-Barr, and influenza ${ }^{36,41,44}$ (CBI/ Mimotopes) and the CMV pp65 peptide mix containing 138 15-mers overlapping by 11 amino acids (Becton Dickinson, San Jose, CA).

Peptide pools (library and array) were prepared for each ORF by grouping peptides linearly across an ORF and were used to screen PBMC, cervical T-cell lines, or T-cell clones. A total of 2,633 peptides were synthesized and grouped into pools composed of peptides ranging from 21 to 100 peptides per pool (median 85 peptides per pool) as previously described. ${ }^{36}$ Array pools, used to deconvolute library pools that were positive in the T-cell screen, were prepared by arranging the peptides within a single library pool in a row-andcolumn format and pooling the peptides in each column or row.

IFN- $\gamma$ ELISPOT. The production of IFN- $\gamma$ by HSV-specific T cells obtained from PBMC or cervical T-cell lines was analyzed by ELISPOT as previously described ${ }^{36}$ with modifications. PBMC were thawed in R10 (RPMI 1640 supplemented with 10\% fetal bovine serum, $2 \mathrm{~mm}$ l-glutamine, $25 \mathrm{~mm}$ HEPES (N-2-hydroxyethylpiperazine- $N^{\prime}-2$ ethanesulfonic acid) buffer, $50 \mu \mathrm{g} \mathrm{ml}^{-1}$ streptomycin, $50 \mathrm{U} \mathrm{ml}^{-1}$ penicillin containing $50 \mathrm{U} \mathrm{ml}^{-1}$ benzonase (Novagen, Madison, WI)], and then washed and rested overnight in $\mathrm{R} 10$ at $37^{\circ} \mathrm{C}, 5 \% \mathrm{CO}_{2}$ before assay. Cervical T-cell lines were washed twice and counted. Using the 
IFN- $\gamma$ ELISPOT kit (Mabtech, Cincinnati, OH) according to the manufacturer's instructions, PBMC were plated at $2 \times 10^{5}$ cells per well (no additional antigen-presenting cells added) and cervical T-cell lines were plated at $5 \times 10^{4}$ cells per well along with $5 \times 10^{4}$ irradiated autologous PBMC as antigen-presenting cells. Peptides were added to the wells at a final concentration of $1 \mu \mathrm{g} \mathrm{ml}^{-1}$ for overnight stimulation. Wells containing R10 alone or R10 and dimethyl sulfoxide served as negative controls, and those containing $1 \mu \mathrm{g} \mathrm{ml}^{-1} \mathrm{PHA}$ served as positive controls. Negative controls were tested in four replicate wells, whereas HSV-2, CMV and cytomegalovirus, EpsteinBarr virus and influenza peptide pools, and PHA were tested in duplicate wells. Spots were counted and analyzed using the automated Bioreader (Biosys GmbH, Karben, Germany). Responses were considered positive if (1) the spot-forming cells (SFC) per well were four times greater than the mean SFC in the four dimethyl sulfoxide wells and (2) the SFC per well was $\geq 11$ SFC per well. ${ }^{36,45}$ Results are expressed as SFC per $10^{6}$ cells.

ICS and flow cytometry. To determine the phenotype of HSV-2 peptide-specific cervically derived T cells, ICS and flow cytometry was performed using a six-color ICS panel in a 96-well plate format modified from ${ }^{46}$ as previously described. ${ }^{36}$ Briefly, in order to assess T-cell responses to whole HSV-2, cervical T-cell lines $\left(0.5-1 \times 10^{6}\right.$ per well) were co-incubated with irradiated autologous lymphoblastoid cell lines that were mock infected (negative control) or infected overnight with HSV-2 at a cell ratio of 10:1; in order to assess HSV-2 peptide-specific T-cell responses, irradiated autologous lymphoblastoid cell lines were co-incubated with HSV-2 peptide pools $\left(1 \mu \mathrm{g} \mathrm{ml}^{-1}\right)$ or individual HSV-2 peptides $\left(1 \mu \mathrm{g} \mathrm{ml}^{-1}\right)$. Controls included dimethyl sulfoxide (negative control), Staphylococcus enterotoxin B (positive control), cytomegalovirus, Epstein-Barr virus and influenza, or CMV peptide pools. During the 6-h incubation at $37^{\circ} \mathrm{C}$, brefeldin A $\left(10 \mu \mathrm{g} \mathrm{ml}^{-1}\right.$, Sigma) and the co-stimulatory antibodies CD28 and CD49d (each at $1 \mu \mathrm{g} \mathrm{ml}^{-1}$, BD Biosciences) were included. Antibodies CD4-FITC, CD8 PerCP-Cy5.5, IFN- $\gamma$ APC, and IL-2 PE were purchased from BD Biosciences, CD3 ECD was purchased from Beckman Coulter (Marseille, France), and the LIVE/ DEAD Fixable Violet Dead Cell Stain was purchased from Invitrogen/ Molecular Probes (Eugene, OR). Samples were collected from 96-well plates using a high-throughput sample (BD) device for analysis by the LSRII and all FACS analyses were performed using FlowJo software (Treestar, Ashland, OR). To be considered positive, IFN- $\gamma$ or interleukin-2 production needed to exceed the background by a factor of at least two. ${ }^{47}$

Measurement of HSV DNA in cervical secretions. CVL fluid collected at both clinic visits from HSVneg and HSV-2 + women was evaluated for HSV DNA by quantitative, real-time, fluorescence-based PCR as described. $^{48}$

Statistical analysis. The Wilcoxon matched-pair signed ranks test was employed to determine the differences between compartments. Statistical significance was defined as $P<0.05$ with a two-tailed $\alpha$ - test.

\section{ACKNOWLEDGMENTS}

This study was supported by the National Institute of Allergy and Infectious Diseases, National Institutes of Health, grants R21 Al-083418 and R01 Al-091701 to C. Posavad, P01 Al-030731 to A. Wald and L. Corey. We thank Dr Amalia Magaret for valuable advice regarding statistical analyses, Dr Betsy Herold for sharing her expertise related to the collection of CVL, Michael Remington for sample collection, Kaile Ross and Emma Robinson for participant scheduling, Stacy Selke for clinical data management, Cindy Hirano and Elizabeth Morrigan for assistance with Institutional Review Board protocols, Kerry Laing for supplying some HSV-2 peptide pools, and Anna Rashevsky for performing the HSV PCR.

\section{DISCLOSURE}

C.M.P. and L.C. are coinventors on several patents involving potential HSV vaccine candidates. L.C. is on the scientific advisory board for and holds stock ( $<1 \%$ of company) in Immune Design Corp. A.W. has received research funding from Gilead, Agenus, Genocea, and Vical and has been a consultant for Aicuris. The remaining authors declared no conflict of interest.

c) 2015 Society for Mucosal Immunology

\section{REFERENCES}

1. Freeman, E.E., Weiss, H.A., Glynn, J.R., Cross, P.L., Whitworth, J.A. \& Hayes, R.J. Herpes simplex virus 2 infection increases HIV acquisition in men and women: systematic review and meta-analysis of longitudinal studies. AIDS 20, 73-83 (2006).

2. Xu, F. et al. Trends in herpes simplex virus type 1 and type 2 seroprevalence in the United States. JAMA 296, 964-973 (2006).

3. Gupta, R., Warren, T. \& Wald, A. Genital herpes. Lancet 370, 2127-2137 (2007).

4. Corey, L. et al. Recombinant glycoprotein vaccine for the prevention of genital HSV-2 infection: two randomized controlled trials. Chiron HSV Vaccine Study Group. JAMA 282, 331-340 (1999).

5. Stanberry, L.R. et al. Glycoprotein-D-adjuvant vaccine to prevent genital herpes. N. Engl. J. Med. 347, 1652-1661 (2002).

6. Johnston, C., Koelle, D.M. \& Wald, A. HSV-2: in pursuit of a vaccine. J. Clin. Invest. 121, 4600-4609 (2011).

7. Johnston, C. et al. Standard-dose and high-dose daily antiviral therapy for short episodes of genital HSV-2 reactivation: three randomised, openlabel, cross-over trials. Lancet 379, 641-647 (2012).

8. Bagdades, E.K., Pillay, D., Squire, S.B., O'Neil, C., Johnson, M.A. \& Griffiths, P.D. Relationship between herpes simplex virus ulceration and CD4 + cell counts in patients with HIV infection. AIDS 6, 1317-1320 (1992).

9. Posavad, C.M., Koelle, D.M., Shaughnessy, M.F. \& Corey, L. Severe genital herpes infections in HIV-infected individuals with impaired herpes simplex virus-specific CD8 + cytotoxic T lymphocyte responses. Proc. Natl. Acad. Sci. USA 94, 10289-10294 (1997).

10. Posavad, C.M. et al. Frequent reactivation of herpes simplex virus among HIV-1-infected patients treated with highly active antiretroviral therapy. J. Infect. Dis. 190, 693-696 (2004).

11. Koelle, D.M., Posavad, C.M., Barnum, G.R., Johnson, M.L., Frank, J.M. \& Corey, L. Clearance of HSV-2 from recurrent genital lesions correlates with infiltration of HSV-specific cytotoxic T Iymphocytes. J. Clin. Invest. 101, 1500-1508 (1998).

12. Koelle, D.M., Abbo, H., Peck, A., Ziegweid, K. \& Corey, L. Direct recovery of herpes simplex virus (HSV)-specific T lymphocyte clones from recurrent genital HSV-2 lesions. J. Infect. Dis. 169, 956-961 (1994).

13. Posavad, C.M., Huang, M.L., Barcy, S., Koelle, D.M. \& Corey, L. Long term persistence of herpes simplex virus-specific CD8 + CTL in persons with frequently recurring genital herpes. J. Immunol. 165, 1146-1152 (2000).

14. Koelle, D.M., Chen, H.B., Gavin, M.A., Wald, A., Kwok, W.W. \& Corey, L. CD8 CTL from genital herpes simplex lesions: recognition of viral tegument and immediate early proteins and lysis of infected cutaneous cells. J. Immunol. 166, 4049-4058 (2001).

15. Zhu, J. et al. Virus-specific CD8 + T cells accumulate near sensory nerve endings in genital skin during subclinical HSV-2 reactivation. J. Exp. Med. 204, 595-603 (2007).

16. Peng, T., Zhu, J., Phasouk, K., Koelle, D.M., Wald, A. \& Corey, L. An effector phenotype of CD8 $+\mathrm{T}$ cells at the junction epithelium during clinical quiescence of herpes simplex virus 2 infection. J. Virol. 86, 10587-10596 (2012).

17. Zhu, J. et al. Immune surveillance by CD8alphaalpha + skin-resident T cells in human herpes virus infection. Nature 497, 494-497 (2013).

18. Schiffer, J.T. et al. Mucosal host immune response predicts the severity and duration of herpes simplex virus-2 genital tract shedding episodes. Proc. Natl. Acad. Sci. USA 107, 18973-18978 (2010).

19. Ouwendijk, W.J., Laing, K.J., Verjans, G.M. \& Koelle, D.M. T-cell immunity to human alphaherpesviruses. Curr. Opin. Virol. 3, 452-460 (2013).

20. Koelle, D.M., Schomogyi, M. \& Corey, L. Antigen-specific Tcells localize to the uterine cervix in women with genital herpes simplex virus type 2 infection. J. Infect. Dis. 182, 662-670 (2000). 
21. Sathaliyawala, T. et al. Distribution and compartmentalization of human circulating and tissue-resident memory $\mathrm{T}$ cell subsets. Immunity $\mathbf{3 8}$ 187-197 (2013).

22. Johansson, E.L., Rudin, A., Wassen, L. \& Holmgren, J. Distribution of lymphocytes and adhesion molecules in human cervix and vagina. Immunology 96, 272-277 (1999).

23. Kyongo, J.K. et al. Searching for lower female genital tract soluble and cellular biomarkers: defining levels and predictors in a cohort of healthy Caucasian women. PLoS One 7, e43951 (2012).

24. McKinnon, L.R. et al. Optimizing viable leukocyte sampling from the female genital tract for clinical trials: an international multi-site study. PLoS One $\mathbf{9}$ e85675 (2014).

25. Levine, W.C. et al. Increase in endocervical CD4 lymphocytes among women with nonulcerative sexually transmitted diseases. J. Infect. Dis. 177, 167-174 (1998).

26. Bere, A., Denny, L., Hanekom, W., Burgers, W.A. \& Passmore, J.A. Comparison of polyclonal expansion methods to improve the recovery of cervical cytobrush-derived T cells from the female genital tract of HIVinfected women. J. Immunol. Methods 354, 68-79 (2010).

27. Martinelli, E. et al. HSV-2 infection of dendritic cells amplifies a highly susceptible HIV-1 cell target. PLoS Pathog. 7, e1002109 (2011).

28. McKinnon, L.R. \& Kaul, R. Quality and quantity: mucosal CD4 + T cells and HIV susceptibility. Curr. Opin. HIV AIDS 7, 195-202 (2012).

29. Rebbapragada, A. et al. Negative mucosal synergy between Herpes simplex type 2 and HIV in the female genital tract. AIDS 21, 589-598 (2007).

30. Tanton, C. et al. Patterns of herpes simplex virus shedding over 1 month and the impact of acyclovir and HIV in HSV-2-seropositive women in Tanzania. Sex. Transm. Infect. 87, 406-411 (2011).

31. Aumakhan, B. et al. Genital herpes evaluation by quantitative TaqMan PCR: correlating single detection and quantity of HSV-2 DNA in cervicovaginal lavage fluids with cross-sectional and longitudinal clinical data. Virol. J. 7, 328 (2010).

32. Keller, M.J. et al. Changes in the soluble mucosal immune environment during genital herpes outbreaks. J. Acquir. Immune. Defic. Syndr. 61, 194-202 (2012).

33. Bere, A., Denny, L., Burgers, W.A. \& Passmore, J.A. Polyclonal expansion of cervical cytobrush-derived T cells to investigate HIV-specific responses in the female genital tract. Immunology 130, 23-33 (2010).

34. Hosken, N. et al. Diversity of the CD8 + T-cell response to herpes simplex virus type 2 proteins among persons with genital herpes. J. Virol. 80 , 5509-5515 (2006).
35. Laing, K.J. et al. Diversity in CD8(+) T cell function and epitope breadth among persons with genital herpes. J. Clin. Immunol. 30, 703-722 (2010).

36. Posavad, C.M. et al. Detailed characterization of Tcell responses to herpes simplex virus-2 in immune seronegative persons. J. Immunol. 184, 32503259 (2010).

37. Posavad, C.M. et al. T cell immunity to herpes simplex viruses in seronegative subjects: silent infection or acquired immunity? J. Immunol. 170, 4380-4388 (2003).

38. Jing, L. et al. Cross-presentation and genome-wide screening reveal candidate Tcells antigens for a herpes simplex virus type 1 vaccine. J. Clin. Invest. 122, 654-673 (2012).

39. Morrow, R.A. \& Friedrich, D. Inaccuracy of certain commercial enzyme immunoassays in diagnosing genital infections with herpes simplex virus types 1 or 2. Am. J. Clin. Pathol. 120, 839-844 (2003).

40. Morrow, R.A., Friedrich, D., Meier, A. \& Corey, L. Use of "biokit HSV-2 Rapid Assay" to improve the positive predictive value of Focus HerpeSelect HSV-2 ELISA. BMC Infect. Dis. 5, 84 (2005).

41. Bull, M. et al. Defining blood processing parameters for optimal detection of cryopreserved antigen-specific responses for HIV vaccine trials. J. Immunol. Methods 322, 57-69 (2007).

42. Posavad, C.M. \& Rosenthal, K.L. Herpes simplex virus-infected fibroblasts are resistant to and inhibit cytotoxic T-lymphoyte activity. J. Virol. 66, 62646272 (1992).

43. John, M. et al. Cervicovaginal secretions contribute to innate resistance to herpes simplex virus infection. J. Infect. Dis. 192, 1731-1740 (2005).

44. Currier, J.R. et al. A panel of MHC class I restricted viral peptides for use as a quality control for vaccine trial ELISPOT assays. J. Immunol. Methods 260, 157-172 (2002).

45. Moodie, Z., Huang, Y., Gu, L., Hural, J. \& Self, S.G. Statistical positivity criteria for the analysis of ELISpot assay data in HIV-1 vaccine trials. J. Immunol. Methods 315, 121-132 (2006).

46. Horton, $\mathrm{H}$. et al. Optimization and validation of an 8-color intracellular cytokine staining (ICS) assay to quantify antigen-specific Tcells induced by vaccination. J. Immunol. Methods 323, 39-54 (2007).

47. Kaul, R. et al. Quantitative ex vivo analysis of functional virus-specific CD8 T lymphocytes in the blood and genital tract of HIV-infected women. AIDS 17, 1139-1144 (2003).

48. Jerome, K.R., Huang, M.L., Wald, A., Selke, S. \& Corey, L. Quantitative stability of DNA after extended storage of clinical specimens as determined by real-time PCR. J. Clin. Microbiol. 40, 2609-2611 (2002). 